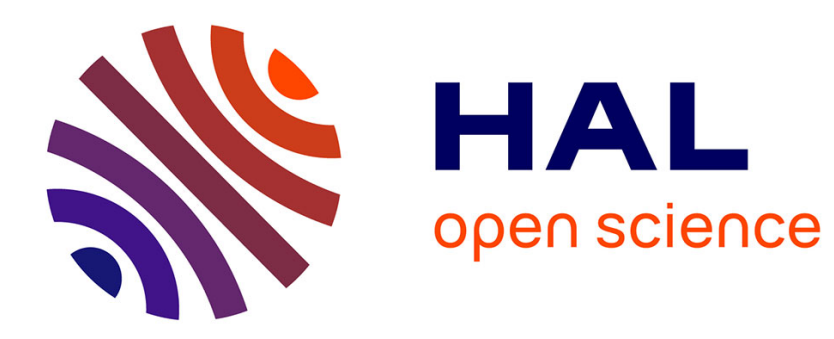

\title{
LIGHT SCATTERING FROM MOTILE BACTERIA
}

R. Nossal, Si Chen

\section{To cite this version:}

R. Nossal, Si Chen. LIGHT SCATTERING FROM MOTILE BACTERIA. Journal de Physique Colloques, 1972, 33 (C1), pp.C1-171-C1-176. 10.1051/jphyscol:1972131 . jpa-00214921

\section{HAL Id: jpa-00214921 https://hal.science/jpa-00214921}

Submitted on 1 Jan 1972

HAL is a multi-disciplinary open access archive for the deposit and dissemination of scientific research documents, whether they are published or not. The documents may come from teaching and research institutions in France or abroad, or from public or private research centers.
L'archive ouverte pluridisciplinaire HAL, est destinée au dépôt et à la diffusion de documents scientifiques de niveau recherche, publiés ou non, émanant des établissements d'enseignement et de recherche français ou étrangers, des laboratoires publics ou privés. 


\title{
LIGHT SCATTERING FROM MOTILE BACTERIA
}

\author{
R. NOSSAL \\ Physical Sciences Laboratory, Division of Computer Research \\ and Technology, National Institutes of Health, Bethesda \\ Maryland, 20014, U. S. A. \\ and S. H. CHEN \\ Department of Nuclear Engineering, Massachusetts Institute of Technology, \\ Cambridge, Massachusetts 02139, U. S. A.
}

Résumé. - Nous démontrons que la « fonction intermédiaire de diffusion 》, $l(\mathbf{K}, t)$, de la lumière diffusée par des bactéries mobiles peut s'exprimer de la façon suivante: $I(\mathrm{~K}, t)=\int_{0}^{\infty} \frac{\sin K V t}{K V t} P_{\mathrm{s}}(V) \mathrm{d} V$, (1) où $P_{\mathrm{s}}(V)$, est la distribution de la vitesse de natation des bactéries. Nous avons étudié les spectres de la lumière diffusée par des échantillons de bactéries $E$. Coli $\mathrm{K}_{12}$ mobiles. Ces spectres ont été obtenus par une méthode spectroscopique ( laser ) dans laquelle nous mesurons l'autocorrélation de l'intensité de la lumière diffusée. Nous démontrons que la relation entre les spectres expérimentaux et leurs vecteurs d'onde de diffusion satisfait l'équation (1). Par contre, les bactéries qui sont immobilisées par l'addition de $10^{-2} \mathrm{M} \mathrm{CuCl}_{2}$ donnent des spectres qui ont les caractéristiques du mouvement Brownien des grosses particules.

On peut déterminer $P_{\mathrm{S}}(V)$ en appliquant la transformation de Fourier inverse à l'expression obtenue pour $I(K, t)$. On indique comment varie la distribution $P_{\mathrm{S}}(V)$ lorsque l'environnement est modifié.

\begin{abstract}
The «Intermediate scattering function » $I(\mathbf{K}, t)$ of light scattered by motile bacteria is shown to be $I(\mathbf{K}, t)=\int_{0}^{\infty} \frac{\sin K V t}{K \bar{V} t} P_{\mathrm{s}}(V) \mathrm{d} V$, (1) where $P_{\mathrm{s}}(V)$ is the distribution of swimming speeds of the bacteria. Scattercd spectra from motile $E$, Coli $\mathrm{K}_{12}$ bacteria have been investigated by laser light intensity correlation spectroscopy. $[I(\mathbf{K}, t)]^{2}$ is obtained from the data and its angular dependence is shown to agree with that predicted theoretically by eq. (1). In contrast, bacteria whose motility has been arrested by addition of $10^{-2} \mathrm{M} \mathrm{CuCl}_{2}$ are found to scatter light with a spectrum characteristic of large Brownian particles.

The swimming speed distribution $P_{\mathrm{S}}(V)$ may be determined by performing appropriate Fourier inversions of the data taken from the motile bacteria. The manner by which the distribution changes when environmental factors are varied is indicated.
\end{abstract}

We have been using laser light intensity correlation spectroscopy to determine various quantities related to the motility of bacteria. Particular attention has been given to the longitudinal swimming speed distribution of the bacteria $P_{S}(V)$, which is especially easy to obtain. In the following we first review the theoretical relationships between $P_{\mathrm{s}}(V)$ and the intermediate scattering function $I(\mathbf{K}, t)$. The latter may be obtained directly from the light scattering data, and we discuss various measurements of bacterial motion based upon these considerations. We also report upon a prelimi- nary experiment showing the possibility of studying the chemotactic responses of the bacteria.

Motile strains of $E$. Coli $\mathrm{K}_{12}$ bacteria [1] are of specific interest to us. When these bacteria are observed under a microscope they appear to move at constant speed in straight lines. These motions persist for times of the order of seconds before the bacteria change directions. Such times are long when compared with typical decay times of bacterial scattering spectra. Consequently, for the purpose of calculating $I(\mathbf{K}, t)$, one may assert that the velocities of the individual 
bacteria remain unchanged over measurement times relevant to the scattering experiments. It is then particularly easy to calculate $I(K, t)$, since the effect of the bacteria simply is to cause a Doppler shift of the frequency of the laser beam [2], [3].

Indeed, for such a homogeneous sample of swimming bacteria, $I(\mathbf{K}, t)$ is given as

$$
\begin{aligned}
I(\mathbf{K}, t) & =|A|^{2}\left\langle\sum_{\text {Bacteria }} \mathrm{e}^{-i \mathbf{K} \cdot R_{i}(0)} \mathrm{e}^{-i \mathbf{K} \cdot R_{j}(t)}\right\rangle \\
& =N|A|^{2}\left\langle\mathrm{e}^{i \mathbf{K} \cdot \mathbf{v} t}\right\rangle
\end{aligned}
$$

where $\mathbf{V}$ is the bacterial velocity, $\mathbf{K}$ is the Bragg wave vector, and $t$ is the time. If no external forces are acting upon the bacteria, the velocity distribution is isotropic, and we have

$$
\begin{aligned}
\left\langle\mathrm{e}^{i \mathrm{~K} . \mathrm{V} t}>\right. & \equiv \int_{0}^{\infty} \int_{0}^{\pi} \int_{0}^{2 \pi} \mathrm{e}^{i K V t \cos \theta} \sin \theta\left[V^{2} P(V)\right] \times \\
& \times \mathrm{d} V \mathrm{~d} \theta \mathrm{d} \varphi \\
& =\int_{0}^{\infty} \frac{\sin K V t}{K V t}\left[4 \pi V^{2} P(V)\right] \mathrm{d} V .
\end{aligned}
$$

Upon identifying the swimming speed distribution $P_{\mathrm{S}}(V)$ as

$$
P_{\mathrm{s}}(V)=4 \pi V^{2} P(V),
$$

then $I(\mathbf{K}, t)$ may be written as

$$
I(\mathbf{K}, t)=\int_{0}^{\infty} \frac{\sin K V t}{K V t} P_{\mathrm{S}}(V) \mathrm{d} V,
$$

in a form normalized to the value $I(\mathbf{K}, 0)=1$.

A laser light intensity correlation spectrometer, specially designed and constructed by one of us (S. H. Chen), was employed in this study. The source for this spectrometer is a well stabilized $\mathrm{He}-\mathrm{Ne}$ laser (Spectra-Physics model 125) operating in the $\mathrm{TEM}_{00}$ mode $(\lambda=6328 \AA)$. The sample rests in a temperature controlled bath (in these experiments the stability was $\pm 0.1^{\circ} \mathrm{C}$ ). Scattered light at various scattering angles $\theta$ is collimated by two pinholes of $0.2 \mathrm{~mm}$ diameter, approximately $50 \mathrm{~cm}$ apart, and is detected by an ITT F-4085 phototube having a $0.35 \mathrm{~mm}$ circular photocathode. The loss of spatial correlation of the light at the photodetector in this geometry is only about $5 \%$. The output of the phototube is processed by a set of fast amplifiers and a fast dicriminator to produce a series of standardized short pulses (50 ns wide, $5 \mathrm{~V}$ amplitude), each pulse corresponding to detection of a photon. These pulses are then fed into a digital autocorrelator which computes the « clipped autocorrelation function $»$ at 128 delay time points simultaneously.

The correlator measures, essentially, the expected number of counts at the delay time $\tau$, given that at $\tau=0$ there are more than $k$ counts within a counting period $T$. This is achieved by spitting the input pulse trains into two routes, clipping the first into a binary sequence, and then performing a delayed coincidence measurement with the second. The schematic circuit diagram of a portion of our 128 channel correlator is given in figure 1. The correlator has buffer storage capacity of 4 bits per channel; the overflow pulse (corresponding to 16 counts) is transferred into the memory of a multichannel analyzer every $1.31 \mathrm{~ms}$. (The control and timing circuits, and the input clipping register, are not shown in figure 1.) The detailed circuit and its operation are to be reported elsewhere [4].

The total counts accumulated in the $j$-th channel $N_{j}$ in the multichannel analyzer is

$$
N_{j}=\eta_{\mathrm{t}}\left\langle n_{k}\left(0 ; T^{\prime}\right) n(j T ; T)\right\rangle
$$

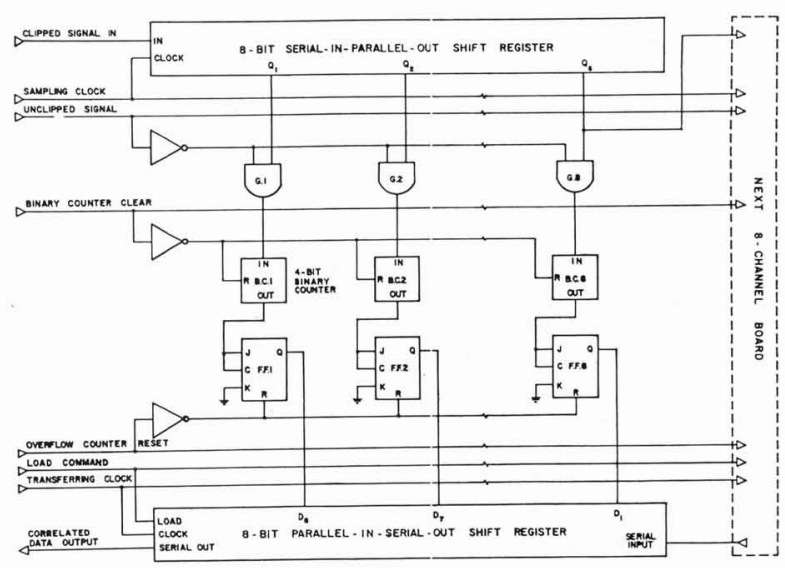

FIG. 1. - Schematic circuit diagram of 8 channels of the digital correlator. G 1 ...G 8 = coincidence gates;FF 1 ...FF 8 = flip-flop overflow counters. The output of the flip-flops are read every $1.31 \mathrm{~ms}$ into the lower shift register, and then transferred serially into the memory of a multichannel analyzer. Thus the data are accumulated continuously and displayed as the experiment progresses.

where $n(\tau ; T)$ is the number of counts at time $\tau$ accumulated over the gating time $T$, and the product $\eta_{1} T$ is the total measurement time. $n_{k}$ has a value of 1 when $n(0, T)>k$ and is otherwise 0 (see Jakeman and Pike [5] for a precise discussion of notation). The uncorrelated d. c. background $N_{\mathrm{B}}$ can be obtained by letting $\tau=j T \rightarrow \infty$, and observing that

$$
N_{\mathrm{B}}=\eta_{\mathrm{t}}\left\langle n_{k}\right\rangle\langle n\rangle=N_{\text {triggex }}\langle n\rangle,
$$

where $N_{\text {trigger }}$ is the number of 1's in the binary sequence and $\langle n\rangle$ is the average number of counts per gating time. Our correlator also registers these numbers during the experiment, so that the uncorrelated background may be unambiguously extracted. Foord et al. [6] have reported an 8-channel correlator built on the same principle. They further showed that, when the statistical nature of the scattered light is Gaussian, aside from a small spatial coherence correction factor one may write

$$
\frac{N_{j}-N_{\mathrm{B}}}{N_{\mathrm{B}}}=\frac{1+k}{1+\langle n\rangle}\left|g^{(1)}(\tau)\right|^{2} \text {. }
$$


In our case $\left|g^{(1)}(\tau)\right|^{2}=I^{2}(K, \tau)$ [7]. For purposes of comparing spectra in these experiments it is useful to normalize $I(K, t)$ such that $I(K, 0)=1$. To accomplish this we simply subtract the uncorrelated background from the total counts of each channel and then normalize the resultant data to unity at $\tau=0$.

Eq. (4) implies that $I(K, t)$ should be a functional of the variable $X=K t$, i. e., if the data taken at different angles are plotted as a function of $X$ rather than as a function of time, they should superimpose. Figure $2 a$ shows scattering data from a motile sample, taken at three different angles. These curves have been obtained from the output of the correlator by subtracting the uniform background according to eq. (6) and then normalizing. The bacteria in this sample seemed to move independently (the sample contained approximately $10^{7}$ bacteria/cc), as indicated by the fact that dilution of the bacteria did not give rise to changes in the normalized scattering spectrum. Thus, although the spectrometer is operated

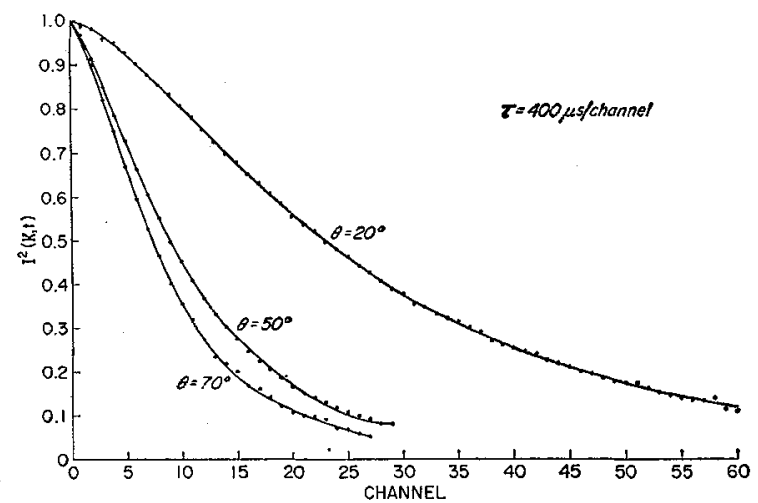

(a)

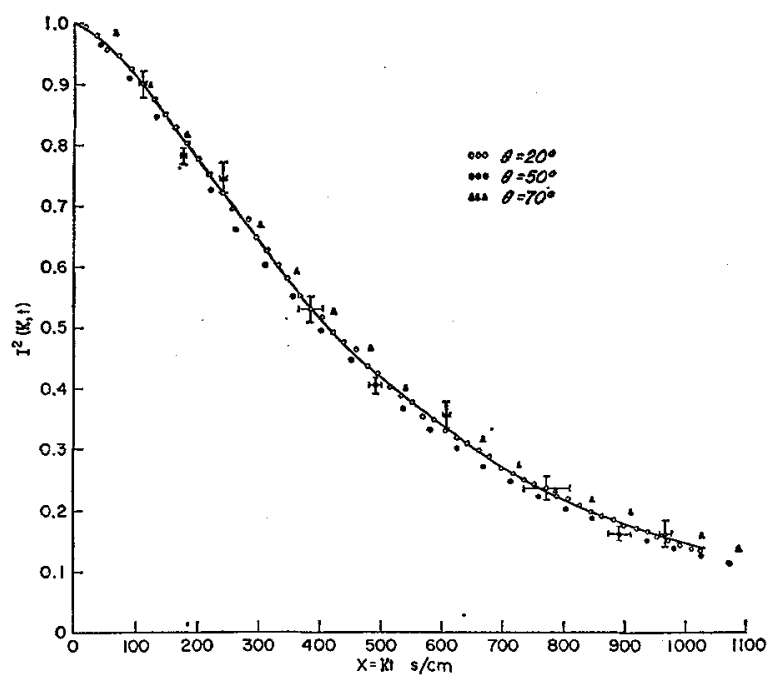

(b)

Fig. 2, - Normalized autocorrelation data for scattering from a liquid culture of motile $E$. Coli $\mathrm{K}_{12}$ bacteria ( $10^{7}$ bacteria $/ \mathrm{ml}$ in L-broth [10], Temp. $=25^{\circ} \mathrm{C}$ ). The scattering volume contained approximately $10^{2}$ bacteria ; clipping level $=0$. A) $I^{2}(K, t)$ for three different scattering angles $\theta$. B) The same data, plotted as a function of the variable $X=K t$. See reference. [11] for further discussion. in the homodyne mode in our experiments, the data given in figure $2 a$ may be directly interpreted as $[I(K, t)]^{2}$. In figure $2 b$ the data are plotted as a function of $X=K t$, and we see that the parametric dependence indicated by eq. (4) is well substantiated.

The Fourier sine transform of eq. (4) yields the swimming speed distribution $P_{\mathrm{S}}(V)$, viz.,

$$
P_{\mathrm{S}}(V)=\frac{2 V}{\pi} \int_{0}^{\infty} \sin X V[X I(X)] \mathrm{d} X .
$$

In figure 3 we show the swimming speed distribution which corresponds to the spectrum presented in figure 2. Parenthetically, we remark that the swimming speed distribution of the bacteria decreases to zero at a much slower rate than does the Maxwellian distribution which has its maximum at the same speed.

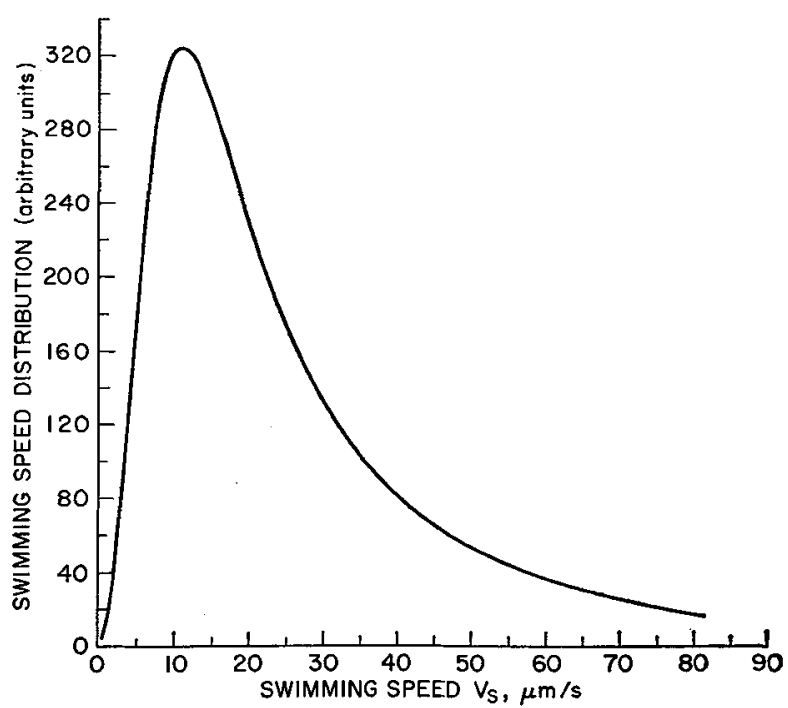

FIG. 3. - The swimming speed distribution $P_{\mathrm{S}}(V)$ obtained from the data presented in figure $2\left(\theta=20^{\circ}\right)$.

The bacteria to which the data of figures 2 and 3 pertain all appeared to be moving when observed under the microscope. In general, a sample may also contain non-motile bacteria. To study the scattering properties of such bacteria, $10^{-2} \mathrm{M} \mathrm{CuCl}_{2}$ was added to a motile sample. After several hours persistent movement had ceased and the bacteria assumed the characteristics of large Brownian particles. Scattering data for this motion-arrested sample are presented in figure 4, where they have been plotted as a function of the variable $Y=K^{2} t$. The curves corresponding to different scattering angles overlap remarkably well.

If the non-motile sample were to consist solely of spherical particles of a single size, the intermediate scattering function would have the form

$$
I(K, t) \sim \mathrm{e}^{-D K^{2} t} .
$$

However, as seen from the inset of figure 4, the data do not quite follow such a simple exponential decay. 


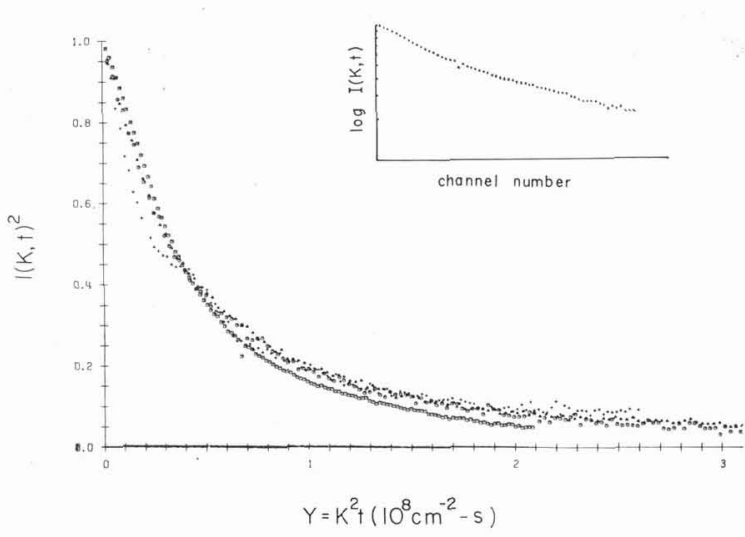

FIG. 4. - Normalized autocorrelation data for non-motile bacteria. The sample was similar to that of figure 2, except that $10^{-2} \mathrm{M} \mathrm{CuCl}_{2}$ was added to cause the bacteria to lose their motility. $I^{2}(K, t)$ plotted as a function of $Y=K^{2} t$ for different scattering angles $\theta$. (Key : $. \cdot \odot \cdot . . . \theta=20^{\circ} ; \odot \odot \odot \odot \ldots$ $\theta=50^{\circ} ; \Delta \triangle \triangle \triangle \ldots \theta=60^{\circ} ;++++\ldots \theta=120^{\circ}$ ). The insert shows $\log I(K, t)$ for $\theta=20^{\circ}$. Note that the autocorrelation

function does not quite follow a simple exponential decay.

The deviation probably is due to heterogeneity of the sample (e. g. clumping of the bacteria, dust, etc.), but the spectrum may also contain components arising from rotational diffusion. On the other hand, an effective value for the longitudinal diffusion coefficient of the non-motile bacteria may be obtained, for example, from the expression

$$
D_{\mathrm{av}}=-\lim _{X \rightarrow 0} I(Y) \frac{\mathrm{d} \ln I(Y)}{\mathrm{d} Y} .
$$

For the sample discussed in figure 4 , such a procedure yields the value $D_{\mathrm{av}}=5 \times 10^{-9} \mathrm{~cm}^{2} / \mathrm{s}$ corresponding to an equivalent Stokes diameter of 1.0 micron.

Of course, a sample will not necessarily be either entirely motile or entirely non-motile. Analysis of the scattering spectra is slightly more difficult when the sample contains both types of particles. However, by taking measurements at different scattering angles, an estimate of the fraction of each component in the sample may be made and, for example, data pertaining only to the motile particles may be extracted. A procedure for unscrambling the two types of spectra is discussed in Appendix A. It is important to take data always at more than a single angle, in order to check on the characteristics of the particles being studied.

Currently, we are gathering data on the manner by which the swimming speed distributions of the bacteria are affected by changes in such parameters as temperature, salinity of the media, and concentrations of metabolites. An example of the change which can be seen in the spectrum is shown in the oscilloscope displays presented in figure $5 a$. These data pertain to the effect of $\mathrm{NaCl}$ on motility. In figure $5 b$, we present a preliminary analysis of some data showing the inhibition of motility resulting from increasing $\mathrm{NaCl}$ concentration.

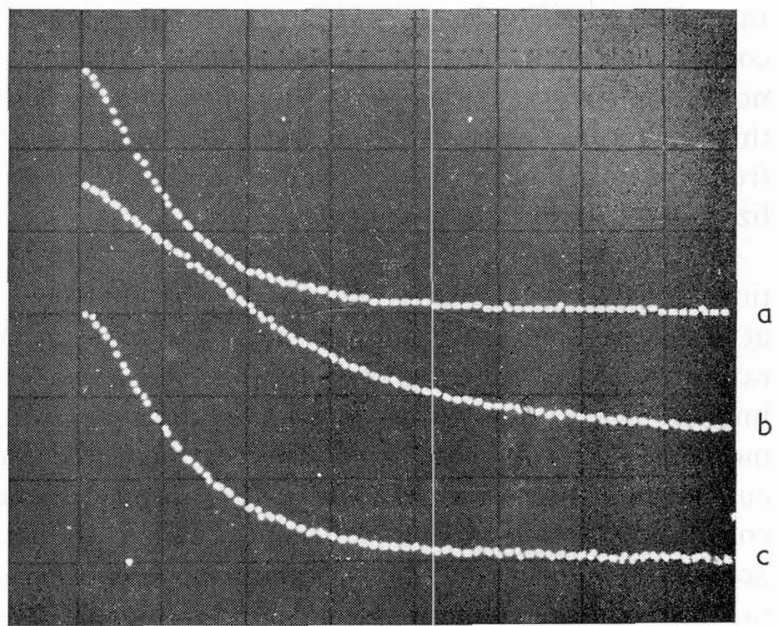

(a)

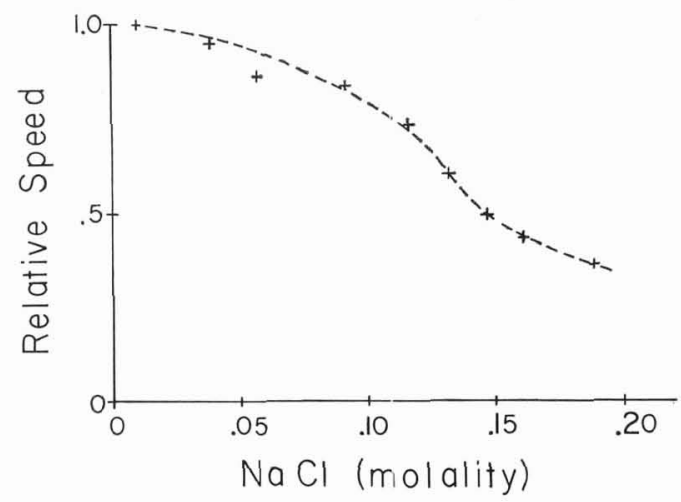

(b)

FIG. 5. - The effect of $\mathrm{NaCl}$ on motility. A) Oscilloscope displays of spectra, showing reversibility of $\mathrm{NaCl}$ inhibition : a) Bacteria in L-broth, Temp. $=25^{\circ} \mathrm{C} ; b$ ) Same sample, only after addition of $.5 \mathrm{M} \mathrm{NaCl}$; c) Same sample, after centrifugation and resuspension in fresh L-broth. B) The relative average velocity of the bacteria, as a function of increasing $\mathrm{NaCl}$ concentration. Bacteria suspended in a «motility medium» [1] consisting of $10^{-4} \mathrm{MEDTA}, 10^{-2} \mathrm{M} \mathrm{KPO}_{4}$ buffer $\mathrm{pH} 7.0$, and $10^{-2} \mathrm{M}$ glucose.

Finally, we should like to report upon some crude experiments which suggest that techniques similar to those discussed above can be applied to study directional responses of the bacteria. In figure 6 we show some photographs illustrating oxygen taxis [8], [9]. Bacteria which had been washed free of broth and resuspended in a medium containing only glucose as an energy source were kept in a closed vial for approximately 24 hours. During this time the oxygen supply in the medium was depleted. Then, an open ended light scattering cell (Precision Cells type 3 ) having a square cross section was completely filled with this sample, and a $0.25 \mu$ millipore filter pasted across the open end. The cell was positioned at an angle of $90^{\circ}$ to the incident beam, first in an upright position and then flat on its side. The spectrum obtained when the cell was upright is shown in figure $6 a$, and those spectra obtained when the cell lay on its side are shown in figure $6 b-d$. 


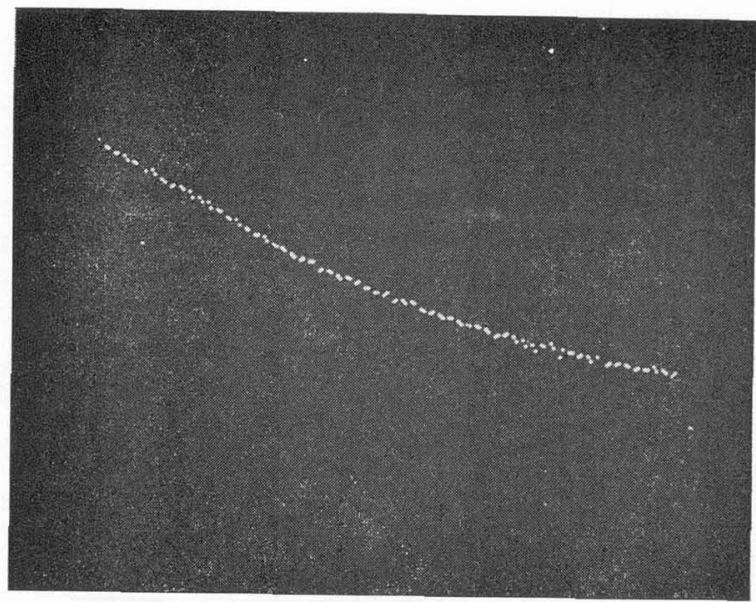

(a)

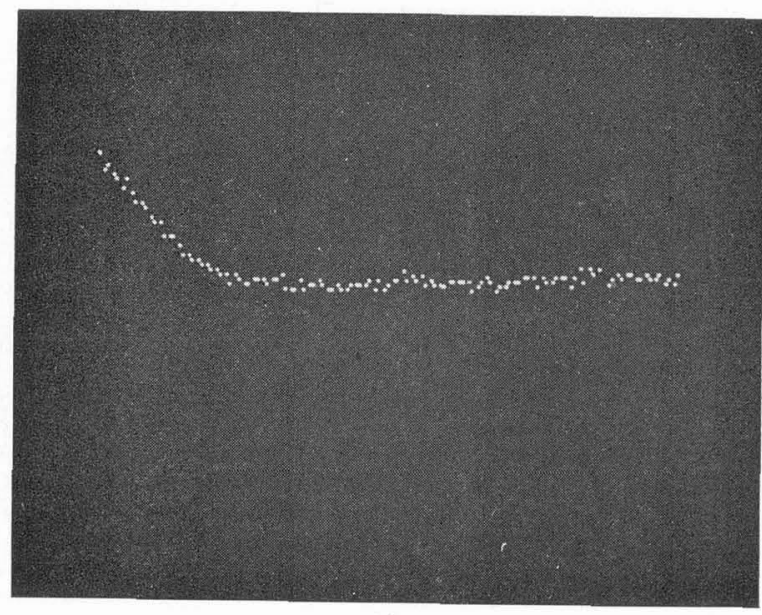

(c)

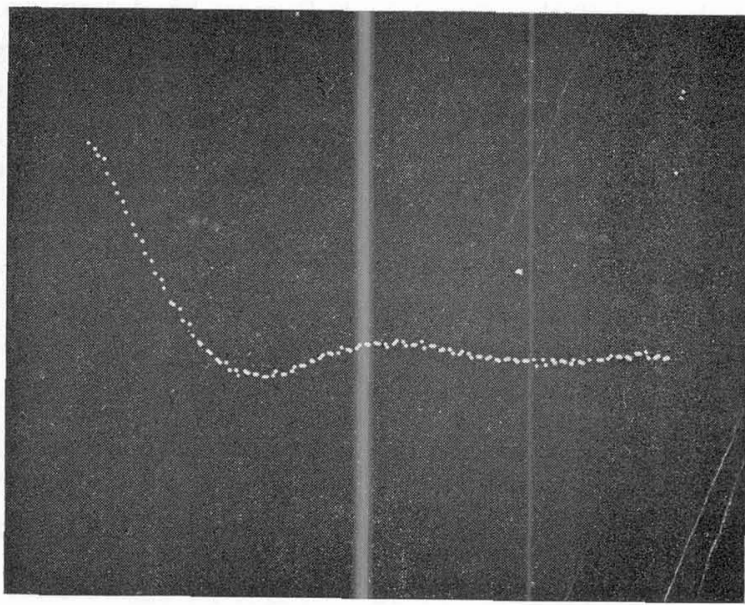

(b)

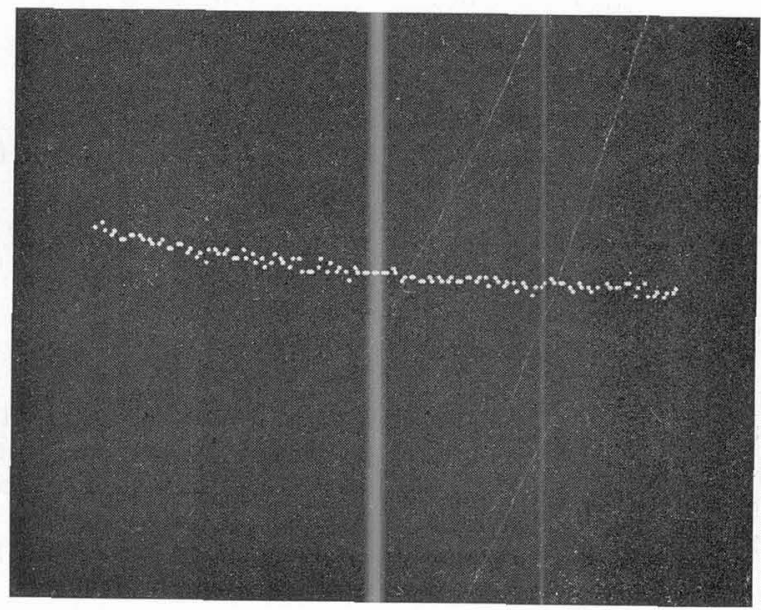

(d)

Fig. 6. - Detection of chemotaxis. a) Scattering from region near the oxygenated surface of the sample. Cell upright, so that chemotactic motion was perpendicular to plane defined by the incident and detected beams. $b$ ) Scattering from the same region of the sample, only the cell was on its side so that chemotactic motion occurred in the plane of detection. c) Cell on its side, but scattering volume farther from the oxygenated end of the cell. d) Cell on side, but scattering volume near the closed end of the: cell. (See text for further discussion.) Scattering angle $\theta$ was $20^{\circ}$ with respect to the incident beam.

The bacteria move in response to the gradients in concentrations of various chemicals [9]. When the scattering cell lies is on its side, the gradient in oxygen concentration occurs in the plane defined by the incident beam and the detected scattered beam ; on the other hand, when the cell is upright the component of motion due to the oxygen taxis is perpendicular to the plane of movement. When the various spectra are compared, the modulation arising from the directional motion associated with the oxygen taxis is clearly seen.

Appendix A. - Mixtures of Motile and Nonmotile Scatterers.

When the scattering sample is composed of a mixed population of motile and non-motile particles, estimates of the properties of each type may be obtained in the following manner. Let us first represent the portion of the spectrum associated with the non- motile particles as a single exponential (cf. Fig. 4). Then, the entire spectrum may be described as

$$
I(\mathbf{K}, t)=\alpha I_{s w}(\mathbf{K}, t)+(1-\alpha) \mathrm{e}^{-K^{2} D t},
$$

where $I_{\text {sw }}$ is the spectrum due to the swimmers, $\alpha$ is the fraction of the scattered light due to the motile particles, and $I(\mathbf{K}, t)$ is normalized so that $I(\mathbf{K}, 0)=1$. If we now rewrite eq. (9) in terms of the variable $X=K t$, we find

$$
I(X)=\alpha I_{\text {sw }}(X)+(1-\alpha) \mathrm{e}^{-K D X} .
$$

Therefore, if data pertaining to two scattering angles are expressed in this way and subtracted one from the other, we find the "difference spectrum » $I_{\mathrm{diff}}(X)$ to be given as

$I_{\text {diff }} \equiv I_{1}-I_{2}=(1-\alpha)\left[\mathrm{e}^{-K_{1} D X}-\mathrm{e}^{-K_{2} D X}\right]$.

When $K_{2}>K_{1}$, eq. (11) has the form shown in figure 7. The quantity $\alpha$ may be determined from the 
maximum of the curve, and $D$ may be determined from the point $X_{M}$ where the maximum occurs (see caption of Fig. 7). The spectrum due only to the swimming particles may be obtained by subtracting the portion arising from the non-motile particles and then renormalizing.

Fig. 7. $-I_{\text {dutr }}(X)$ vs. $X$. Example of a mixed population of motile and non-motile scatterers. The diffusion coefficient may be determined according to $D=\frac{1}{X_{M}\left(K_{1}-K_{2}\right)} \ln K_{1} / K_{2} . \alpha$ may be determined from the expression

$$
\begin{gathered}
I_{\mathrm{diff}}^{\max }=(1-\alpha)\left\{\left(\frac{K_{2}}{K_{1}}\right)^{K_{1} /\left(K_{1}-K_{2}\right)}-\left(\frac{K_{2}}{K_{1}}\right)^{K_{2} /\left(K_{1}-K_{2}\right)}\right\} \\
\left(\theta_{1}=20^{\circ}, \theta_{2}=40^{\circ}\right) .
\end{gathered}
$$

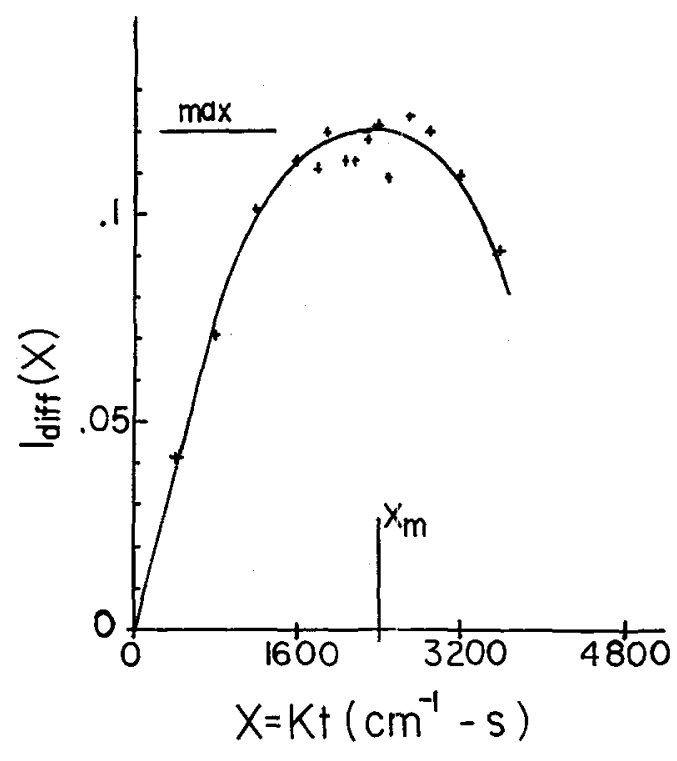

\section{References}

[1] Adler (J.) and Dahl (M. M.), J. Gen. Microbiol., 1967, 46, 161.

[2] Combescot (R.), J. Physique, 1970, 31, 767.

[3] Nossal (R.), Biophys. J., 1971, 11, 341.

[4] CHEN (S. H.) and LAI (C. C.), to appear.

[5] JAKeman (E.) and Pike (E. R.), J. Phys., 1969, A 2, 411.

[6] FOORd (R.), JAKEMAN (E.), OLIVER (C. J.), and PIKE (E. R.), Proceedings Southampton Conference on Lasers and Opto-Electronics, 1969 ;

Foord (R.), JAKEMAN (E.), OLIVER (C. J.), PIKe (E. R.),
Blagrove (R. J.), Wood (E.) and PesCOCKE (A. R.), Nature, 1970, 227, 242.

[7] Chen (S. H.) and Polonsky-Ostrowsky (N.), Optics Comm., 1969, 1, 64.

[8] WeiBull (C.), The Bacteria, I. C. Gunsalus and R. Y. Stanier, Ed. (Academic Press, New York, 1960), v. I, p. 153 .

[9] AdLer (J.), Science, 1969, 166, 1588.

[10] LenNox (E. S.), Virology, 1955, 1, 190.

[11] Nossal (R.), Chen (S. H.), I Aa (C. C.), Optics Comm., 1971, 4, 35. 